\title{
Relationship Between Sexual Assault and Development of Eating Disorders in Domestic and International College Women
}

M Jessica Cefalo \& Rose Marie Ward, Ph.D

\section{Introduction}

There is an increased risk of developing an eating disorder among college women. This is especially true when sexual assault has occurred previously. Eating disorders, more specifically, anorexia nervosa (AN) is defined as having a total body weight of less than $85 \%$ of what is considered to be the normal for a person's height and weight, a severe worry of becoming overweight or gaining weight, and the absence of a menstrual cycle for at least three consecutive months. Bulimia nervosa (BN) is defined as eating large quantities of food that would not normally be consumed in such quantities and compensating for that by purging, extreme exercise, or fasting. These actions must take place at least two times a week and last for at least three months in order to be diagnosed. $3-10 \%$ of females will experience some sort of eating disorder in their lifetime (Polivy 2002).

Research has shown that college women are at a higher risk of developing an eating disorder with an estimate of $25 \%$ of women in college having some form of eating disorder symptoms. College women are also at risk of being sexually assaulted, with that estimation being about 19\% (Calam 1988).

Sexual assault can be defined as the force or threat of sexual contact (Boyle 1984). Sexual assault is shown to be one of the major contributors to the development of an eating disorder. A study showed that about $50 \%$ of the sample had experienced some sort of unwanted sexual interaction and were also diagnosed with AN or BN. Many patients reported that the eating disorder was a coping mechanism for dealing with being a victim of sexual assault (Richard 1989). Studies have also shown that recent victims of sexual assault have overestimated the size of their body (Treuer 2005).

PURPOSE: The purpose of this study is to determine the relationship between sexual assault and the development of an eating disorder in domestic and international college women.

\section{Methods}

\section{Procedure}

This study was conducted at a Midwestern university. 2,144 females completed the survey. Participants were given a series of questionnaires to measure their unwanted sexual experiences and eating habits.

\section{Participants}

A majority of the respondents identified as heterosexual $(85.9 \%, n=1,841)$. Participants were asked to identify if they were an international student, in which $13.5 \% \quad(n=289)$ said yes and $85.5 \%(n=1,834)$ said no. The average age of the participants was 19.89 ( $S D=1.54)$.

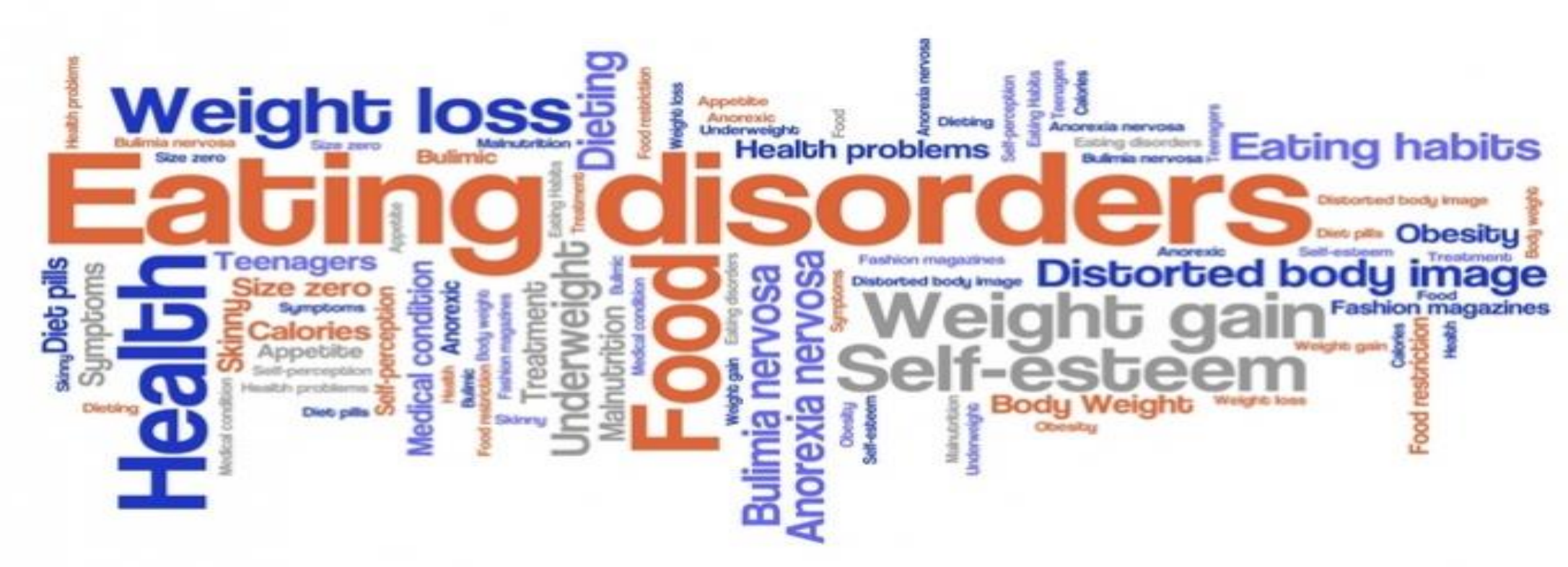

\section{Results}

$55.5 \%$ ( $n=1189)$ of women identified as not being a victim of sexual assault. This does not include women who experienced unwanted sexual contact to the severity increasing to rape.

Approximately $17.5 \%$ ( $n=376)$ of women scored a 2.00 or higher on the SCOFF which indicates the need for further evaluation of potential eating disorders.

The regression that predicts eating pathology from international students and victim status was significant, $F(2.1697)=16.64, p<0.001$. Victim status $(\beta=0.14, p<0.001)$ significantly predicted eating pathology but international status did not $(\beta=0.04, p=0.08)$.

\section{Discussion}

The results of this study showed that eating disorder pathology relates to a sexual assault history. The results support my hypothesis that college women who are sexually assaulted are more likely to develop an eating disorder. The results showed that it did not matter if one was a domestic or international student, they still had the same likelihood of developing an eating disorder after being sexually assaulted. What differed was that International students were less likely to be sexually assaulted in the first place but they were not less likely to develop an eating disorder after the sexual assault occurred.

Limitations of this study was that there was no previous research that analyzed the prevalence rates of eating disorders and sexual assault in both domestic and international students. Previous research focused in more on domestic college women only. Another limitation was that the SCOFF scale only contained 5 questions. The small amount of questions meant that only two questions needed to be answered "yes" in order to go on to further diagnosis. Other questions would have possibly gone into more detail about the women's eating disorder symptoms.

\section{Acknowledgements}

Special thanks to Dr. Rose Marie Ward and the Department of Kinesiology and Health, who made this research possible

Author Contact-cefalojl@miamioh.edu 